\title{
Introduction: between law, ageing and ageism
}

\section{Israel (Issi) Doron and Nena Georgantzi}

\section{PROLOGUE}

This book is about law, ageing and ageism in Europe. Generally speaking, European countries, as well as the European public media and interest are well aware of the ageing of Europe, the demographic shift it is facing, and the future challenges which are related. Nevertheless, much less attention was given in Europe to the social construction of old age, the prejudices, biases, stigmas and discrimination the older Europeans experience in their daily lives. Moreover, the different European legal systems, for example legislators, judges and lawyers, were mostly unaware of or blind to the fact that older persons have unique legal challenges, and that these challenges are the outcome of the way society treats and constructs old age.

\section{LAW AND AGEING}

Historically, law - meaning lawyers, judges, legislators or the scientific or philosophical (jurisprudential) aspects of the legal body of knowledge - was not interested in "ageing" or "older persons" as such (Doron, 2008). Typically, the interface between law and the older population was within the broader context of treating the poor, those who were unable to care for themselves (for example "lunatics" or "idiots"), or in the context of filial responsibility (for example the duty to care for older parents who were not able to care for themselves) (Doron, 1998). Even in more modern times, when law and society started to recognize the significance of "social groups" as the societal way of systematically discriminating (for example based on religion, nationality, gender, sexual orientation or disability), "age", a unique legal category, was usually missing or invisible (Rodriguez-Pinzon and Martin, 2002). 
This reality has changed dramatically since the 1970s. Beginning in the USA (Frolik, 1993), and then spreading to Canada (Herring, 2016; Soden, 2005), the UK (Foster et al., 2014), and other common-law jurisdiction, and finally reaching continental Europe in recent years, the field of "law and ageing" (or "elder law") had gained visibility and recognition within the legal discipline, the legal profession and beyond. New books, publications, research centres, private-bar associations, highprofile legal cases, and media appearances have all been seen in recent years in the field of law and ageing in Europe (Mikołajczyk, 2013; Numhauser-Henning, 2013b).

This change or shift of reality is commonly attributed to three key developments: First, the demographic shift and its socio-legal implications. At this stage of history, it is quite clear that one of the most important global challenges for the 21st century is global ageing. All over the globe societies are experiencing the combination of a dramatic increase of life expectancy, along with a sharp decline in fertility rates (and, for some countries, this combines with either internal migration of young people to big cities, or international immigration of young people to richer countries). The overall outcome of these trends is no less than dramatic: a significant growth both in total numbers, as well as with relative percentage rates, of the older population (Kalache et al., 2005). This historical development could not have been ignored by law, and the various "actors" within this field have started to either be exposed to it (for example older persons' issues coming to courts or raising public legal debates), or are becoming interested in it (as part of looking for new clientele or a unique field of expertise). Older persons themselves have also started not only to organize, but to voice their claim for the legal recognition of their human rights.

Second, the recognition of the private bar, law firms and lawyers to the potential needs of older clientele: the demographic rise of older persons and their role and place in societies have naturally given rise to the interest of private lawyers in this population. In an ever growing competitive legal world, with growing numbers of lawyers, there is a constant search for new legal fields, with potential economic gain. More and more private lawyers have come to recognize the potential legal interest that older persons bring with them to the field of law. Specifically, within the American context, ageing comes with very specialized knowledge in fields such as the right to healthcare in old age (for example, programmes like Medicaid, which is the unique healthcare insurance for poor, older Americans, which is legally very complicated), or in the field of estate planning (focused more on the rich who look for 
means to evade inheritance tax or to transfer assets while evading the tax system) (Frolik, 1993).

Academia and the world of science have also realized that there are unique theoretical, methodological and empirical issues in the inter- and multi-disciplinary study of law and ageing. Both lawyers and gerontologists have realized that one cannot fully understand the interaction between legal systems and the lives of older persons without combining both social and legal bases of knowledge (Doron, 2006).

Finally, these developments did not remain at national level, but appeared at international level as well. More specifically, and as argued by Sciubba (2014), norm diffusion from Latin America to the international level and from the debate and passage of the Convention on the Rights of Persons with Disabilities (CRPD) steered some awareness of rights in older age and drove the campaigning around a convention.

The outcome of all these developments has been expressed in a growing interest in improving the knowledge, the data, the theories and the methodologies within the field of law and ageing in recent years.

\section{AGEISM}

But what is it in old age that makes it interesting for law? Why do older people "deserve" to be recognized as a distinct societal group which receives "special" legal treatment? These are actually very important questions for the field of elder law. The answers are not simple and some would argue that indeed there is no such justification. However, as we will try to argue below, there is some justification to realize that older persons experience a unique social phenomenon which raises a legitimate concern for a proper rights-based response.

At least one justification would be found in the social concept of "ageism". In recent years there has been a significant growth in interest and research in this field. This book is based upon work from COST Action IS1402, supported by COST (European Cooperation in Science and Technology), which was fully dedicated to looking into the various aspects of ageism (www.cost.eu). Hence it is beyond the scope of this chapter to fully cover the rich knowledge and understanding of this phenomenon. However, in order to provide the basic foundations which will provide the theoretical context for the rest of this book, we will try to provide some key aspects of this term.

From a definitional perspective, the first to coin the term "ageism" and to attempt to define it was Dr Robert Butler. One of his best known early definitions for the term was as follows: 
Just as racism and sexism are based on ethnicity and gender, ageism is a form of systematic stereotyping and discrimination against people simply because they are old. As a group, older people are categorized as rigid in thought and manner, old fashioned in morality and skills. They are boring, stingy, cranky, demanding, avaricious, bossy, ugly, dirty and useless. An ageist younger generation sees older people as different from itself; it subtly ceases to identify with its elders as human beings. (Butler, 1969)

Since Dr Butler's original definition many other attempts were made to define ageism, mirroring the growing understanding of the phenomenon. One of the more recent definitions in the field reflects these newer definitional developments well:

Ageism is defined as negative or positive stereotypes, prejudice and/or discrimination against (or to the advantage of ) elderly people on the basis of their chronological age or on the basis of a perception of them as being 'old' or 'elderly'. Ageism can be implicit or explicit and can be expressed on a micro-, meso-, or macro-level. (Iversen et al., 2009)

While the definitional task is ongoing, another important journey began with trying to explain the reasons and foundations of ageism. Various theoretical approaches have been proposed in recent years. Some have focused on the psychology of the individual, for example the Social Identity Theory (SIT) with its understanding of the importance of group identity for the individual, while allowing the creation of the "young" group identity as opposed to the "old" group (Bodner, 2009). Others have focused on the more macro or institutional and societal levels, such as the capitalistic organization of the modern society, and its division and segregation of functional age groups (for example, young - trained for production; mature - actively productive and breeding the future workers; old - non-productive and inactive) (Hagestad and Uhlenberg, 2005).

One of the more well-known individual-level based theories which tries to explain the phenomenon of ageism is the TMT - Terror Management Theory. This theory stresses the psychological human nature and its fear of death. From that perspective, in many ways ageing and older persons are the real face and reminder of death, which most of us either deny or try to avoid (Burke et al., 2010).

Finally, while the challenges of both defining and explaining ageism continue, yet another growing body of research has been conducted into the ways in which ageism manifests itself in everyday life. Indeed numerous studies in the field of healthcare have shown how physicians, nurses, physiotherapists and more, not only hold ageist attitudes towards 
older patients, but also operate in discriminatory ways, providing older patients with inappropriate care (Inbar et al., 2012; Topaz and Doron, 2013).

Overall, then, it seems that current theoretical and empirical knowledge points to the fact that one cannot ignore both the existence of ageism and its real life consequences on the lived experience of older Europeans. One cannot understand the full meaning of "being old" without taking into account how society views and values older persons.

\section{LAW AND AGEISM}

If we realize that for various reasons the field of "law and ageing" has emerged in recent years, and that we have a much better awareness and understanding of the social phenomenon of ageism, this raises the obvious question: how do they both interact or interrelate? As a matter of fact, one can conceive of various points of potential interactions, which we will try to describe below.

\section{Statutory Law and Other Binding Legal Instruments}

One of the key means by which law operates is statutory law (or legislation). From a sociology of law perspective, one can learn a great deal about the values and cultures of societies simply by looking into the language of their black-letter laws. More specifically, within the context of ageism and legal rights of older persons, one could argue that "show me your laws, and I'll know how ageist you are".

Various specific examples exist on the books of national legislation which reflect ageist attitudes towards older persons. Such examples can be found in the absence of "age" within human rights and equality legislation (Rodriguez-Pinzon and Martin, 2002); in legislation which allows or even mandates workforce retirement solely based on chronological age (Numhauser-Henning, 2013a); in statutory frameworks which use chronological age limits (for example for transplantation) (Katvan et al., 2017); or in social protection legislation which allows for the nomination of a guardian over older persons as part of the notion that they cannot take care of themselves because of their age (Doron, 2004).

Interestingly, the ways in which ageism shapes legislation can be found not only at the local or national levels, but also at the international, regional and global level. The simplest examples can be found in the fundamental human rights texts. For example, at the UN level, key legal instruments such as the Universal Declaration of Human Rights, or the International Covenant on Economic, Social and Cultural Rights either 
do not mention "age" as a unique category (within the context of right to equality) or mention "age" in a very limited and narrow context. For example, according to General Comment No. 6 of the International Covenant on Economic, Social and Cultural Rights, age discrimination is prohibited only in several contexts and not in all, which is completely different language from that used for the General Comment on disability, for instance, which includes a clear prohibition of discrimination based on disability.

More specifically, at the European level, the European Convention of Human Rights also does not include a specific article regarding the rights of older persons, and its "equality" article does not mention "age" as a specific category (Spanier et al., 2013). Moreover, prior to 2009 and the coming into force of the Lisbon Treaty, the European Charter of Fundamental Rights also did not include a specific article regarding older persons as such, and their rights were specifically referred to in a very limited way (Doron, 2013).

A very recent example of the interplay of ageism and binding legal instruments has been displayed on the international level within the context of the UN Open-Ended Working Group on Ageing, and the debates around the need for a new and specific international convention for the human rights of older persons (Doron and Apter, 2010). On the one hand, the formation of the Open-Ended Working Group on Ageing in 2010, which was followed by the nomination of an Independent Expert on the enjoyment of all human rights by older persons by the Human Rights Council in 2014, reflected a growing awareness on the global level for the need to legally address the human rights challenges facing older persons. On the other hand, both these bodies have failed so far to be successful in actually promoting the advancement of a new international convention in the field. One potential reason for this failure can be found in an ageist attitude towards human rights of older persons.

\section{Lawyers}

Most people encounter law through the mediation of the legal professional, that is, the lawyers. However, potentially, lawyers (like other professionals) can hold biases, stereotypes and stigma regarding old age and older persons. These personal attitudes can potentially be manifested through discriminatory practices: refusing to accept older clients, treating older clients in a less professional way, adopting more paternalistic approaches in their legal strategies, or even settling cases for lower amounts of money in the view that the "value" of compensation for older clients should be lower than for younger ones. 
Not many empirical studies have been conducted on lawyers with regard to ageism. One study measured both the knowledge and the attitudes of lawyers toward ageing and older persons (Ontzik-Heilburn, and Or-Chen, 2014). The finding showed that lawyers expressed low levels of knowledge in the field of ageing, but at the same time expressed mostly neutral and non-ageist attitudes towards their older clients. One of the key recommendations of this study was the need to study further the ways in which lawyers construct their relationships with older clients.

\section{Judges and Courts}

Eventually, legal disputes surrounding older persons reach the courts. These legal disputes are eventually settled by judges. These judges are potentially also exposed to ageism, and may be influenced both by their own as well as by the broader cultural values and traditions with regard to the meaning and place of ageing in society.

In recent years various new studies have been published that analyzed - both quantitatively and qualitatively - to what extent court rulings represent "ageist" approaches towards older persons. For example, on the European level, quantitative studies of the rulings of the European Court of Human Rights (ECHR) have shown that the ECHR is mostly unaware of or reflects "blindness" to the phenomenon of ageism (Spanier et al., 2013). Qualitative studies have shown more mixed realities. For example, a study into the ways courts in Israel construct dementia found that judges express both stigmatic and anti-stigmatic approaches towards older persons with dementia (Doron et al., 2018).

\section{The "Clients" - the Older Adults}

Like many other gerontological fields, which try to explore the phenomenon of human ageing, the authentic voice of the older population itself is lost. Similarly, for many years, within the field of law and ageing the experience of the older persons themselves within the legal system was not explored or captured. To what extent do older persons themselves experience ageism in their interactions with the legal system?

There are not too many studies which explore this point of view. One such qualitative study was conducted with older women about their legal experience during their divorce proceedings in later life (OhayonGlicksman, 2018). Many of these women reported in the interviews how they experienced a mix of both negative and positive ageism in the way their lawyers and the judges treated them. 


\section{Witnesses and Jury Members}

Finally, it should be reminded that older persons appear before the courts not only as plaintiffs of defendants, but they also appear as witnesses and participate in the judicial process as jurors. These unique legal contexts can raise interesting questions. For example, they may raise questions about how courts "evaluate" (e.g. credibility or truthfulness) the testimony of older persons in the context of an ageist culture. Once again, some studies have been conducted in this field. For example, a study conducted on 1267 undergraduate students who read a case summary and witness statement, while the sex and age of the witness $(49,69,79$ or 89 years) varied, found an age effect for honesty, particularly for comparisons of the 79/89-year-olds versus the 49-year-olds (Mueller-Johnson et al., 2007). However, the study by Kwong See et al. (2001) found that while their study's participants perceived a witness described as young to be more competent than a witness described as old, the opposite was found regarding the description of the witness as honest.

A different question can be raised regarding the attitudes, stereotypes and behaviour regarding older persons within their role as jurors and their actual cognitive performance. Some empirical studies have tried to compare the performance of younger and older jurors. For example, the research by Fitzgerald (2000) has found that age (along with vocabulary and education) influenced performance (for example in the field of recognition memory). However, it also found that simple interventions to improve cognitive performance (for example pre-trial instructions) can improve the performance of older jurors.

\section{CONCLUSION: ABOUT THIS BOOK}

Realizing how complex and diverse are the interconnections between ageing, law and ageism has brought about the creation of this book. From the review provided above one can realize how limited is the existing knowledge, both in general, and - within the European context - in specific. In many ways, the European interest in the specific and focused interactions between law, ageing and ageism is in its infancy. It is against this scientific background that this book attempts to try and start to fill in the existing gaps in this important field.

Therefore, the structure of this book tries to mirror our realization of the different ways one can approach our topic, and was constructed in the following manner. 
The first part of the book is focused more on conceptual or theoretical aspects of how ageism can be related to law.

The book opens with the chapter by Rosie Harding, which explores the concepts of equality and social justice for older people in the context of arguments for and against the need for a new Convention on the Rights of Older Persons. Professor Harding interrogates the effectiveness of different theoretical approaches to equality (equality of resources, equality of recognition, equality of power and equality of condition) that could underpin arguments about the need for new international human rights protection for older people. In evaluating each of these "equality"-based approaches, the chapter demonstrates why each falls short as a justification for a new Convention. In response to the limitations of an equality approach, Professor Harding argues that we need to turn towards an understanding of social justice for older people, and suggests that a capabilities approach, building on the work of Amartya Sen and Martha Nussbaum, offers the most persuasive conceptual basis for a new Convention. Moreover, she argues that the capabilities approach, which requires not only the discursive and rhetorical enunciation of rights but also their substantive realization, is the most effective way to understand equality and social justice for older people.

The book continues with the chapter by Titti Mattsson, with a discussion that focuses on the relationship between vulnerability and ageism in the light of age limits in social welfare legislation. Professor Mattsson investigates the meaning of vulnerability by drawing on Martha Albertson Fineman's vulnerability theory as a starting point for the discussion of how the concept alternatively may be used by researchers as well as policy makers dealing with age-related legal issues in order to maximize the social rights potential for older people. The point of departure for the discussion is the Disability Act in Sweden, which limits disability benefits for those over 65 years old who have disabilities that are considered being part of "normal ageing".

Part I closes with the chapter by Gerard Quinn, Ayelet Gur and Joanne Watson, which looks at new developments in communications theory which potentially unlock - and reveal - the will and preference of people (including older people) who have been hitherto deemed unreachable because of their cognitive impairments. It goes further by looking at emerging evidence about the importance of social capital as a form of support to enable people to remain in control of their own lives. Finally, this chapter emphasizes the importance of community living as a way to break down ageism, and of supporting older persons to be, and remain, in charge of their own lives and as well as life choices. 
The second part of the book moves from the theoretical perspective into the more empirical and descriptive perspective of the interaction between law, ageing and ageism.

The first chapter in this part is by Barbara Mikołajczyk, who describes how the participation of older persons in social life has so far been examined predominantly from the sociological, medical, psychological and economic perspective. Lawyers, apart from labour lawyers, have seldom taken on this issue. The chapter continues by arguing that it has been even more uncommon for international lawyers to touch upon active ageing. In order to fill this gap, this chapter examines whether Europe's two most important organizations, the Council of Europe and the European Union, have adopted effective legal instruments promoting active ageing of Europeans. Therefore, this chapter analyzes regional international law acts (both hard and soft law) of the Council of Europe, as well as the EU legal acts, strategies and programmes, and the ways in which they address ageism.

The next chapter is by Ann Numhauser-Henning, which shows how ageism in working life is a central concern when it comes to active ageing. More specifically, this chapter aims to discuss the relation between the EU ban on age discrimination, European employment law and active ageing strategies. In doing so it draws heavily on some earlier works of Professor Numhauser-Henning and on the premise that there is a special and close connection between ageism - the overall theme of this book - and nondiscrimination regulation on the grounds of age. Discrimination - or discriminatory behaviour - is thus an integral part of most definitions of ageism.

Numhuaser-Henning's chapter is followed by Eugenio Mantovani, Paul Quinn and Paul de Hert, who comment in this chapter on the so-called 2014 Chicago Declaration on the Rights of Older Persons, one of the most recent efforts to establish the human rights status of older persons, and the way it tackles stereotyping, stigmatization and discrimination of older persons. To this end, the authors analyze a series of selected cases drawn from the case law of the ECHR with a view to (trying to) anticipate what a judge, confronted with a controversy involving ageism, would decide. The legal analysis, focused on Articles 14 (Prohibition of discrimination) Article 10 (Freedom of expression), and Article 8 (Right to private and family life). This analysis lends support to the claim that stereotyping and stigmatization are only partially open to influence from human rights law. The force of the law appears otherwise to be limited in contrasting the social manifestation of ageism in stigmatizing expressions and stereotypes. 
The next chapter is an empirical analysis made by Benny Spanier and Israel (Issi) Doron. In this chapter, the authors examine the socio-legal status of older persons in the Council of Europe Member States, as reported by the States themselves. This is made possible by the European Social Charter (Revised), and by the European Committee of Social Rights, which supervizes the reports of the States' compliance with the Charter. The chapter presents the first of its kind quantitative empirical analysis of the Committee's decisions regarding older persons, and provides some insights regarding ageism and the social construction of older persons under the ESC.

The book ends with the chapter by Marijke de Pauw, Bridget Sleap and Nena Georgantzi, which describes how ageism and age discrimination lie at the root of many human rights violations faced by older persons worldwide. The authors argue that addressing these issues is thus essential in ensuring the effective protection of older persons' rights. This chapter therefore explores the link between ageism, age discrimination and the rights of older persons at a practical level. The chapter then identifies the position and recognition of ageism in international policy documents and human rights instruments, as well as within ongoing negotiations on a new international binding treaty that focuses on older persons. It thus aims to demonstrate the lack of attention for the phenomenon that negatively affects older persons, and to provide recommendations on how to strengthen an anti-ageist approach in a potential new UN convention on older persons' rights.

Clearly this book does not cover all the rich and diverse interactions between law, ageing and ageism. However, it provides a rich and diverse picture on various elements of these interactions, both at the European and the international level. In many ways it invites further research and more scientific action in this field. Finally, it will hopefully serve as another support for the promotion of future international binding human rights instruments for older persons.

\section{Acknowledgment}

This publication is based upon work from COST Action on Ageism - A multi-national, interdisciplinary perspective (IS1402), supported by COST (European Cooperation in Science and Technology).

Weblink: www.cost.eu

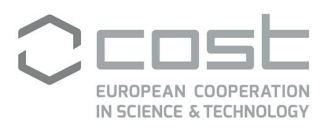




\section{REFERENCES}

Bodner, E. (2009). On the origins of ageism among older and younger adults. International Psychogeriatrics, 21(6), 1003-14.

Burke, B.L., Martens, A. and Faucher, E.H. (2010). Two decades of terror management theory: a meta-analysis of mortality salience research. Personality and Social Psychology Review, 14(2), 155-95.

Butler, R.N. (1969). Age-ism: Another form of bigotry. The Gerontologist, 9(4), 243-6.

Doron, I. (1998). From lunacy to incapacity and beyond. Health Law in Canada, 19(4), 95-114.

Doron, I. (2004). Aging in the shadow of the law: the case of elder guardianship in Israel. Journal of Aging \& Social Policy, 16(4), 59-77.

Doron, I. (2006). Bringing the law to the gerontological stage: a different look at movies and old age. International Journal of Aging \& Human Development, 62(3), 237-54.

Doron, I. (2008). Theories on Law and Ageing: The Jurisprudence of Elder Law. Berlin: Springer.

Doron, I. (2013). Older Europeans and the European Court of Justice. Age and Ageing, 42(5), 604-608.

Doron, I. and Apter, I. (2010). The debate around the need for an international convention on the rights of older persons. The Gerontologist, 50(5), 586-93.

Doron, I., Werner, P., Spanier, B. and Lazar, O. (2018, forthcoming). The meaning of dementia in Israeli court cases: A qualitative analysis. Dementia: the International Journal of Social Research and Practice.

Fitzgerald, J.M. (2000). Younger and older jurors: The influence of environmental supports on memory performance and decision making in complex trials. The Journal of Gerontology - Series B, 55(6), 323-31.

Foster, C., Herring, J. and Doron, I. (2014). The Law and Ethics of Dementia. Bloomsbury Publishing.

Frolik, L.A. (1993). The developing field of elder law: a historical perspective. The Elder Law Journal, 1, 1-18.

Hagestad, G.O. and Uhlenberg, P. (2005). The social separation of old and young: a root of ageism. Journal of Social Issues, 61(2), 343-60.

Herring, J. (2016). Vulnerable Adults and the Law. Oxford: Oxford University Press.

Inbar, N., Doron, I. and Ohry, A. (2012). Physiotherapists' attitudes towards old and young patients in persistent vegetative state (PVS). Quality in Ageing and Older Adults, 13(2), 111-24.

Iversen, T.N., Larsen, L. and Solem, P.E. (2009). A conceptual analysis of ageism. Nordic Psychology, 61(3), 4-22.

Kalache, A., Barreto, S.M. and Keller, I. (2005). Global Ageing: The Demographic Revolution in all Cultures and Societies. In M.L. Johnson (ed.), The Cambridge Handbook of Age and Ageing (pp. 30-46). Cambridge: Cambridge University Press. 
Katvan, E., Doron, I., Ashkenazi, T., Boas, H., Carmiel-Haggai, M., Elhalel, M.D., Schnoor, B. et al. (2017). Age limitation for organ transplantation: the Israeli example. Age and Ageing, 46(1), 8-10.

Kwong See, S.T., Hoffman, H.G. and Wood, T.L. (2001). Perceptions of an old female eyewitness: Is the older eyewitness believable? Psychology and Aging, 16(2), 346-50.

Mikołajczyk, B. (2013). Is the ECHR ready for global ageing? The International Journal of Human Rights, 17(4), 511-29.

Mueller-Johnson, K., Toglia, M.P., Sweeney, C.D. and Ceci, S.J. (2007). The perceived credibility of older adults as witnesses and its relation to ageism. Behavioral Sciences \& the Law, 25(3), 355-75.

Numhauser-Henning, A. (2013a). The EU ban on age-discrimination and older workers: Potentials and pitfalls. International Journal of Comparative Labor Law and Industrial Relations, 29, 391-423.

Numhauser-Henning, A. (2013b). An introduction to elder law and the Norma Elder Law Research Environment. European Journal of Social Law, 2013(3), $235-52$.

Ohayon-Glicksman, H. (2018). Grey Divorce: The Divorce Experience of Older Women Under Israeli Family Law. Thesis submitted for Master's degree in Gerontology [Hebrew]. University of Haifa, Haifa.

Ontzik-Heilburn, I. and Or-Chen, K. (2014). Approach to elderly clients among lawyers in Israel: Attitude towards the elderly and knowledge concerning the elderly among lawyers [Hebrew]. Gerontology \& Geriatrics, 41(3), 31-49.

Rodriguez-Pinzon, D. and Martin, C. (2002). The international human rights status of elderly persons. The American University International Law Review, 18, 915-1008.

Sciubba, J.D. (2014). Explaining campaign timing and support for a UN Convention on the Rights of Older People. The International Journal of Human Rights, 18(4-5), 462-78.

Soden, A. (2005). Advising the Older Client. Markham, Ontario: LexisNexis Butterworths.

Spanier, B., Doron, I. and Milman-Sivan, F. (2013). Older persons' use of the European Court of Human Rights. Journal of Cross-Cultural Gerontology, 28(4), 407-20.

Topaz, M. and Doron, I. (2013). Nurses' attitudes toward older patients in acute care in Israel. Online Journal of Issues in Nursing, 18(2). 